\title{
Aprendizagem da docência: um estudo com professores do curso pré-vestibular da UFSCAr
}

\section{Learning to teach: a study with teachers of a preparatory course for the entrance exam of the Federal University of Sao Carlos}

\author{
Alessandra Cardoso de Moraes* \\ Rosa Maria M. Anunciato de Oliveira**
}

\begin{abstract}
Resumo: Trata-se, este artigo, de uma investigação sobre o processo de aprendizagem da docência de sete professores licenciados e não licenciados do Curso Pré-Vestibular da Universidade Federal de São Carlos (CPV), com o objetivo de analisar as aprendizagens construídas pelos professores no exercício da docência. Apoia-se em estudos sobre a formação de professores, concebendo que a aprendizagem da docência ocorre num continuum por meio da reflexão, na e sobre a ação pedagógica e seu contexto. Foram realizados questionários e entrevistas focalizando como os professores percebem a própria prática. Os resultados mostram que os professores modulam o ensino de acordo com as demandas dos alunos e a análise da experiência vivida ao se envolverem em espaços que, devido à forma de gestão e organização que caracteriza o CPV, extrapolam o âmbito da sala de aula.
\end{abstract}

Palavras-chave: Formação de professores. Aprendizagem profissional. Curso Pré-Vestibular Popular.

Abstract: This article discusses the process of learning to teach of seven graduate and non-graduate teachers of the preparatory entrance exam of the Federal University of Sao Carlos (UFSCAr) with the aim of understanding the kind of learning that takes place during teaching. The investigation was based on studies about teacher education that view learning to teach as a continuous process that involves reflection during practice, about the teaching practice and its context. Questionnaires and interviews were used with teachers in order to understand how they see their own practice. The results show that teachers change their teaching according to students' demands and according to the analysis of

* Doutoranda. Mestre em Educação pelo Programa de Pós-Graduação em Educação da Universidade Federal de São Carlos (UFSCar), área de concentração Processos de Ensino e Aprendizagem.

Moraes desenvolve pesquisas sobre Formação de Professores e outros agentes educacionais. Professora das séries iniciais da Educação Básica em escolas públicas estaduais em São Paulo e professora no curso de Pedagogia Distância - Universidaed Aberta do Brasil (UAB), programa sob a responsabilidade da UFSCar.

E-mail: moraes.ale@gmail.com

* Doctoral student, master in Education from the Post-Graduate Program in Education from the Federal University of Sao Carlos (UFSCAr), area of concentration Teaching and Learning Processes. Moraes carries out research about Teacher Education and other educational agents. Teacher of early years at Basic Education in mainstream public schools in Sao Paulo and professor at the Distance Pedagogy course - Open University of Brazil (UAB), a program under the responsibility of UFSCAr. Email: moraes.ale@gmail.com

** Professora do Departamento de Metodologia de Ensino e do Programa de Pós-Graduação em Educação da Universidade Federal de São Carlos (UFSCar). Oliveira desenvolve pesquisas sobre Formação de Professores e outros agentes educacionais.

E-mail: rosa@ufscar.br

** Professor at the Teaching Methodology Department and of the Post-Graduate Program in Education at the Federal University of SãoCarlos(UFSCAr). Oliveira carries outresearchaboutTeacherEducation and other educational agents. Email: rosa@ufscar.br 
their experiences in contexts such as the preparatory entrance exam that due to their management and organization go beyond the classroom.

Keywords: Teacher education. Professional learning. Preparatory course for university entrance exam.

\section{Introdução}

Na investigação sobre a aprendizagem da docência de professores do Curso Pré-Vestibular da UFSCar (CPV) ${ }^{1}$, procurou-se responder à seguinte questão: "Como ocorre a aprendizagem da docência de professores do Curso Pré-Vestibular da UFSCar na perspectiva dos mesmos?" Por meio dos dados obtidos em entrevista com os participantes, são descritas e analisadas as suas concepções sobre a própria prática docente, sua relação com os alunos, com os pares e com os elementos da formação e do contexto que influenciam suas aprendizagens como docentes, tendo como referência estudos sobre a formação de professores. Os participantes indicam as mudanças ocorridas ao longo do tempo na sua própria prática docente e os pontos que consideram revistos e melhorados. Indicam também suas percepções sobre o CPV e os diferentes tipos de participação no mesmo, bem como analisam algumas relações que podem ser estabelecidas com a experiência desenvolvida nesse projeto.

Inicialmente, será esboçado o quadro teórico do estudo sobre a aprendizagem da docência a partir das contribuições de Imbernón (2000), Marcelo Garcia (1998), Mizukami (2002), Nóvoa (1991), Tardif (2000), Zeichner (1993) e outros. Fazem parte dessa revisão teórica conceitos relativos à reflexão, às teorias práticas, à base de conhecimento etc. Em seguida, é apresentado o estudo realizado: local,

${ }^{1}$ O CPV é uma atividade de extensão do Núcleo UFSCar Escola e sob a coordenação de uma professora do Departamento de Metodologia de Ensino (DME) da mesma universidade. participantes, coleta e análise dos dados, visando compreender as aprendizagens construídas pelos professores no exercício da docência. Finalmente são detalhados os dados obtidos, os quais revelam como a atuação em espaços que extrapolam o âmbito da sala de aula devido à forma de gestão e organização que caracteriza o CPV impactou a docência dos professores participantes.

\section{Aprendizagem da docência: algumas contribuições teóricas}

Atualmente, a concepção que temos sobre a profissão docente passa por transformações. Segundo Nóvoa (1991, p.133), a imagem tradicional desse profissional como “(...) fonte e fornecedor de conhecimentos torna-se caduca; ela é substituída por uma concepção multifuncional do docente, em que diferentes papéis se misturam: formador, animador, organizador, mediador do encontro etc.”.

Imbernón (2000) complementa as proposições de Nóvoa afirmando que o foco da profissão docente no século XIX era a mera transmissão de conhecimento, e as instituições educativas se caracterizavam por serem centralistas, selecionadoras, individualistas etc. Nessa perspectiva, possuir um conhecimento formal era suficiente para assumir a capacidade de ensiná-lo.

O enfoque da definição da docência contemporânea está na valorização dos 
[...] aspectos contextuais, organizativos e orientados para a mudança, o que obriga a conjugar as dimensões individuais da atividade pedagógica às do trabalho em equipe, entendendo que a construção do saber docente se dá na relação dialética entre o individual e o coletivo; o princípio da indagação-reflexão (Knowles, Cole \& Presswood, 1994), que facilita a tomada de consciência dos professores sobre suas práticas de ensino; a natureza colaborativa dos papéis assumidos por parceiros; a especificidade da prática docente que exige construção de soluções não padronizadas; a influência das concepções dos professores na compreensão dos eventos da sala de aula e nas suas práticas pedagógicas; o desenvolvimento da autonomia; a necessidade de se estabelecer uma base de conhecimentos que possibilite o desenvolvimento profissional; a construção do conhecimento pedagógico dos conteúdos dos diferentes componentes curriculares. (MIZUKAMI et al., 1998, p. 501).

Diante disso, a literatura educacional sobre o pensamento do professor apresenta um modelo para a formação de professores, por meio da reflexão, levando-se em conta os conhecimentos produzidos pelos professores ao longo de sua formação, que se iniciaria em sua experiência como aluno, perpassando a formação inicial e continuando ao longo de sua carreira.

Alguns estudos da literatura educacional, como os desenvolvidos por Shulman, Schön, Calderhead, Knowles et al. (apud MIZUKAMI, 2002), Marcelo Garcia (1998), Tardif (2000), Zeichner (1993), entre outros, dedicam-se a investigar o 'pensamento do professor', teoria que envolve conceitos como ensino reflexivo, conhecimento prático, reflexão, teorias práticas, base de conhecimento e tipos de conhecimentos profissionais do professor. Em tal perspectiva, a aprendizagem da docência é entendida como um continuum, iniciando-se antes da preparação formal, prosseguindo ao longo desta e permeando toda a prática profissional vivenciada.

Conceber a aprendizagem da docência como um continnum significa compreender que a experiência tem papel de destaque nesse processo, pois é por meio desta que os professores constroem seus conhecimentos profissionais de forma individual e processual, incorporando e superando o conhecimento oriundo da racionalidade técnica.

A formação básica constitui um dos momentos que compõem o processo formativo, porém não é o único, uma vez que o professor, de acordo com Tancredi (2008, p.21), ao iniciar sua carreira, não possui todos "os conhecimentos, atitudes, habilidades e valores que necessita para ensinar e ser professor, porque não é suficiente para ensinar, conhecer o conteúdo e as técnicas”.

As fontes de aprendizagem da docência, portanto, extrapolam o âmbito da formação básica. Imbernón (2000) e Tancredi (2008) concordam que os conhecimentos dos professores sobre o ensino têm origem em diversos momentos, como: a) na experiência como discentes - aprendem com os professores que fizeram parte de sua trajetória escolar; b) no curso de formação inicial; c) na iniciação da docência - consolidação de um determinado conhecimento profissional (esquemas, pautas, rotinas da profissão); d) na troca de experiência com os pares escolares; e) na prática - os professores aprendem com a reflexão que fazem sobre si mesmos, sobre os alunos, a proposta da escola, entre outros; f) na implantação de políticas educacionais; e g) na formação permanente - para Imbernón (2000, p. 59) "seu objetivo é remover o sentido pedagógico comum, a fim de recompor o equilíbrio entre os esquemas práticos e os esquemas teóricos que sustentam a prática educativa”. 
Conforme Mizukami et al. (2002), a reflexão oferece oportunidade para que as teorias práticas do professor, base de sua prática em sala de aula, sejam gradualmente objetivadas.

Considerando que qualquer processo reflexivo é orientado por conhecimentos, valores e crenças relacionados ao continuum do processo de formação vivenciado por cada professor, pode-se afirmar que no processo de desenvolvimento e aprendizagem da docência a reflexão é particular - pessoal e contextualizada.

Em estudos sobre o desenvolvimento profissional docente, as teorias práticas do professor, de acordo com Sanders \& Mccutcheon (1986 apud MIZUKAMI et al., 2002, p. 50), representam as

[...] estruturas conceituais e visões que oferecem aos professores razões para agir como agem e para escolher as atividades de ensino e materiais curriculares que escolhem de forma a serem efetivos. São princípios e proposições que subjazem às e que guiam as apreciações, decisões e ações dos professores.

Enfim, nesse processo os docentes aprendem a ensinar e a ser professores atendendo a demandas diferenciadas ao atuarem em uma instituição complexa: a escola. Assim, por meio da reflexão e objetivação das teorias práticas, os professores configuram os conhecimentos para o ensino na medida em que aprendem a ser professores ao longo de sua prática.

O modo como os professores constroem seus conhecimentos sobre o ensino tem sido objeto de pesquisas em Educação, mais especificamente na área da formação de professores, evidenciando que suas crenças, experiências e teorias tácitas (implícitas) constituem elementos importantes na configuração da prática docente.
Um dos focos de análise dessas pesquisas é a compreensão da construção do conhecimento pedagógico do conteúdo pelos professores, que se constitui a partir do conhecimento da matéria e do conhecimento pedagógico que o professor possui. Isto é, os professores, ao transformarem o conhecimento do conteúdo específico em práticas pedagógicas - imprimindo ritmo, selecionando o conteúdo a ser ensinado, utilizando-se de representações, exemplos, dentre outros estão construindo o conhecimento pedagógico do conteúdo. Trata-se de uma construção pessoal e processual que exige tomada de decisões, influenciada pelo contexto escolar e pelas teorias tácitas dos professores sobre o ensino, a matéria, os alunos etc.

Apoiando-se em Borko e Putnam (1996), Mizukami et al. (2003, p.67 e 68) apresentam as definições desses conceitos difundidos por Shulman (1986). Para as autoras, o conhecimento pedagógico geral envolve os conhecimentos que o professor possui sobre o ensino, a aprendizagem, os alunos, "incluindo o manejo de classe, estratégias instrucionais para conduzir aulas e criar ambientes de aprendizagem e conhecimento e crenças mais fundamentais sobre os estudantes, sobre como eles aprendem e sobre como a aprendizagem pode ser propiciada pelo ensino". O conhecimento de conteúdo específico envolve os conhecimentos dos conceitos básicos que o professor possui sobre a matéria a ser ensinada, a influência desta nas demais disciplinas do currículo e a construção da estrutura dessa área determinada do conhecimento.

As autoras evidenciam também que os professores constroem novas compreensões da matéria ao longo do exercício profissional, influenciados pelo conhecimento do currículo, pelo conhecimento do aluno, pelo conhecimento pedagógico, assim como pelos conhecimentos de outras áreas correlatas à 
matéria que lecionam. Unem-se, portanto, as compreensões que o professor possui sobre a matéria, sobre recursos, estratégias e representações que utiliza para ensinar. Assim, é construído o conhecimento pedagógico do conteúdo, que tem papel determinante na aprendizagem e no desenvolvimento profissional docente.

Os estudos apontam que os professores iniciantes manifestam dificuldades em transformar os conteúdos aprendidos em práticas pedagógicas. Ao iniciarem suas carreiras, os professores sentem-se desamparados e inseguros frente à realidade escolar com a qual se deparam, pois frequentemente ela não corresponde aos esquemas ideais obtidos no curso de formação inicial para a docência. Esteve (1995, p.109), apoiando-se em Veenman (1984), define a ruptura do esquema ideal sobre o ensino como "choque com a realidade”, entendendo essa fase vivida pelos professores iniciantes como "o colapso das idéias missionárias forjadas durante o curso de formação de professores, em virtude da dura realidade da vida quotidiana na sala de aula”. Esse mesmo conceito é compreendido por Huberman como fase de sobrevivência e descoberta.

Nessa perspectiva, Grossman e Richert (apud RICHERT; SHULMAN; WILSON, 1987, p.114) indicam que, na sequência esperada, os professores iniciantes movem-se de uma compreensão pessoal dos fatos para uma compreensão enriquecida dos novos conhecimentos que eles obtêm de diversas fontes, como as da sua formação e das suas experiências.

Retratar a formação de professores é uma difícil tarefa devido à complexidade de conhecimentos e ações educativas que envolvem o ser professor e o ensinar. É uma questão que não se esgota, e os trabalhos desenvolvidos sobre essa temática não são conclusivos, não encerram as discussões sobre o início da carreira, suas dificuldades e o rol de aprendizagens que constituem o desenvolvimento profissional docente, por exemplo. Com o objetivo de compreender as aprendizagens construídas pelos professores no exercício da docência em um curso pré-vestibular popular, foi realizado tal estudo junto a sete professores que ministram diferentes disciplinas e que são oriundos de diferentes cursos de formação inicial, tanto de licenciatura como de bacharelado.

A seguir, será apresentada uma breve descrição da estrutura e do funcionamento do projeto CPV, dos objetivos e da proposta pedagógica norteadores do seu desenvolvimento.

\section{Local da pesquisa: o Curso Pré-Vestibular da UFSCar}

O projeto Curso Pré-Vestibular da UFSCar foi implantado em 1999. Inicialmente, foram oferecidas 120 vagas à população de São Carlos e região, e em 2005 a oferta de vagas chegou a cerca de 400 .

O CPV possui dois objetivos centrais: dar atendimento à população com condições socioeconômicas desfavorecidas da cidade de São Carlos e região, por meio de um curso preparatório para os vestibulares, e propiciar a essa população maiores chances de acesso às universidades públicas. Visa, ainda, oferecer aos alunos da universidade oportunidade de formação docente sistemática, de longa duração, orientada e supervisionada por docentes da UFSCar.

O público alvo do CPV é composto por estudantes que já tenham concluído o ensino médio ou estejam cursando a última série dessa modalidade de ensino; e, como já se fez referência, que sejam oriundos de camadas com características socioeconômicas menos favorecidas da população de São Carlos 
e região. Esses estudantes ingressam no curso via um processo de seleção composto por: (1) avaliação socioeconômica, feita a partir de informações dos candidatos e comprovada por documentos exigidos aos mesmos; e (2) avaliação de habilidades básicas de leitura, escrita e cálculo matemático elementar, realizada por meio de uma prova com questões de múltipla escolha. O processo seletivo é realizado pela comissão coordenadora e pelo corpo docente do cursinho.

O corpo docente é composto por alunos regularmente matriculados na UFSCar. Não há prioridade para a graduação ou para os cursos de licenciatura. Nessa perspectiva, o corpo docente é caracterizado por apresentar diversidade tanto em termos de formação inicial - graduandos (a maioria) ou pós-graduandos - quanto às áreas de formação.

O corpo docente conta com professores e monitores que atuam em duplas e compartilham responsabilidades relacionadas ao planejamento do ensino, à elaboração e correção de avaliações de aprendizagem dos alunos e à seleção ou elaboração de materiais de ensino.

No texto do projeto, sua gestão é definida como participativa, tanto em relação aos processos decisórios como em relação às responsabilidades na realização das atividades administrativas. Foi organizada uma comissão coordenadora que passou a se responsabilizar pela realização das atividades de rotina administrativa, além de coordenar reuniões pedagógicas e reuniões gerais.

As reuniões pedagógicas são reservadas para a realização de atividades com o corpo docente, relativas à elaboração de questões de testes simulados, ao ensino de conceitos e a discussões sobre 'quem é' o aluno do cursinho e suas necessidades e expectativas; o papel do corpo docente na aprendizagem dos alunos; como ocorre o aprendizado; algumas questões latentes quanto às relações professor-aluno e professor-professor; a ética e a avaliação do projeto em termos da aprendizagem dos alunos; a disciplina em sala de aula, entre outros temas desenvolvidos.

As reuniões gerais caracterizam-se como assembleias gerais, em que todos os integrantes do projeto podem participar e se posicionar, votando nas propostas mais eficazes à tomada de decisão. Assim, todas as ações gerais do projeto dependem de um processo democrático de discussão e decisão, seus participantes precisam assumir as responsabilidades decorrentes desse processo e não são raros, também, os problemas relacionados às dificuldades de realizar um trabalho coletivo e democrático.

Por meio de decisões coletivas, os alunos da universidade planejam e desenvolvem o trabalho, decidem quais atividades seriam mais interessantes para serem desenvolvidas com os alunos, decidem como elas serão realizadas, quando deverão ocorrer e quem deverá ser responsável por viabilizar o trabalho.

\section{A pesquisa}

Partindo do pressuposto de que a aprendizagem da docência é pessoal, particular e contextualizada (MIZUKAMI et al., 2000), é pertinente investigar como ocorre a aprendizagem de professores do Curso Pré-Vestibular da UFSCar em sua perspectiva. Para compreender as aprendizagens construídas pelos professores no exercício da docência no CPV foram definidas três categorias de análise: o início da docência, as mudanças ocorridas em suas práticas e a influência do contexto do CPV.

$\mathrm{O}$ estudo baseou-se nos pressupostos da pesquisa qualitativa. Nesta, a perspectiva 
dos participantes sobre o processo de aprendizagem da docência e a influência do contexto (CPV) no processo mereceram destaque. Bogdan e Bicklen (1994, p. 48) afirmam que os investigadores qualitativos “entendem que as ações podem ser melhor compreendidas quando são observadas no seu ambiente habitual de ocorrência. [...] Para o investigador qualitativo divorciar o ato, a palavra ou o gesto do seu contexto é perder de vista o significado”.

De acordo com os mesmos autores, uma pesquisa qualitativa caracteriza-se essencialmente por ser descritiva, por possuir como principal instrumento o investigador, por obter dados no ambiente natural - no caso, o local de trabalho dos professores - e por ter como foco de interesse do pesquisador o processo e não o produto. Além disso, para Bogdan e Bicklen (1994, p. 50) há uma tendência para analisar os dados de forma indutiva, isto é, os pesquisadores "não recolhem dados ou provas com o objetivo de confirmar ou informar hipóteses construídas previamente; ao invés disso, as abstrações são construídas à medida que os dados particulares que foram recolhidos vão se agrupando”.
Finalmente, como o significado é imprescindível nessa abordagem, o investigador interessa-se por saber como o sujeito da pesquisa interpreta suas experiências; quais são elas; de que maneira os professores - no caso deste estudo especificamente - transformam os conhecimentos que possuem em conhecimentos ensináveis, por exemplo.

Participaram do estudo sete professores. Destes, quatro possuem formação inicial em licenciatura e três não possuem. Quatro atuam na mesma área de conhecimento de sua formação inicial e três atuam em áreas diferentes à de formação em nível superior.

Algumas características do processo de aprendizagem profissional vivido pelos participantes são comuns a todos, ou a parte deles. O corpo docente é formado pelos professores que são licenciados, considerados pela literatura em início de carreira por possuírem menos de cinco anos de prática docente, e por aqueles que estão em processo de formação inicial, ou seja, são graduandos, sendo esta categoria composta pelos licenciandos e os não-licenciandos.

Distribuição da caracterização dos professores do Curso Pré-Vestibular da UFSCar. 2004

\begin{tabular}{|c|c|c|c|}
\hline $\begin{array}{c}\text { Participante } \\
\text { (Nomes fictícios) }\end{array}$ & Formação Inicial & $\begin{array}{c}\text { Atuação no } \\
\text { Cursinho' }\end{array}$ & $\begin{array}{c}\text { Tempo de atuação } \\
\text { no magistério }\end{array}$ \\
\hline Daniel & Licenciatura em Física & Física & 1 ano e 6meses \\
\hline Vitor & Bacharelado em Ciências Sociais & História & 4 anos \\
\hline Eduardo & Licenciatura em Ciências Biológicas & Biologia & 2 anos e 6 meses \\
\hline Márcio & Bacharelado em Física & Física & 2 anos \\
\hline Letícia & Licenciatura em Pedagogia & Geografia & 1 ano \\
\hline Samuel & Engenharia Química & História & 1 ano \\
\hline André & Licenciatura em Matemática & Matemática & 4 anos \\
\hline
\end{tabular}

Fonte: MORAES, A. C. de. “Aprendizagem da docência: um estudo com professores do Curso PréVestibular da UFSCar”. UFSCar, 2005.

A seleção dos participantes da referida pesquisa foi realizada tendo em vista a diversidade de trajetórias pessoais, profissionais e de formação do corpo docente, 
assim como as diferentes participações e experiências no projeto Curso Pré-Vestibular da UFSCar, de acordo com os seguintes critérios: (1) situação no curso de formação inicial (licenciados, não-licenciados, licenciandos e não-licenciandos); (2) área de atuação no projeto, relacionada à área de formação; (3) experiência com monitoria, anterior à atuação docente; e (4) orientação recebida por especialistas.

\section{Procedimentos de coleta e análise de dados}

A coleta de dados para essa pesquisa foi realizada no período de março a outubro de 2004, envolvendo questionário para caracterização da formação dos participantes: sua trajetória escolar - rede privada ou pública, curso de formação inicial (ano de ingresso e conclusão), atuação profissional (tipo de vínculo, disciplinas, nível de ensino e escolas que leciona ou lecionou).

No segundo momento, foram realizadas entrevistas semiestruturadas para analisar como os professores percebem a própria prática, suas estratégias de ensino, quais conhecimentos utilizam para ensinar e como analisam o processo vivido.

A entrevista foi composta por questões nas quais os participantes relataram o início de sua carreira, o local, as dificuldades encontradas, a influência do curso de formação em suas práticas, seu olhar sobre os processos vividos no projeto e no curso de formação inicial, reflexões sobre a prática que desenvolvem, bem como seus planos futuros enquanto professores.

Para Bogdan e Biklen (1994), pautados em Morgan (1998), a entrevista consiste em uma conversa intencional entre o pesquisador e o seu sujeito de pesquisa, ou entre aquele e um determinado grupo de professores, por exemplo. Ludke e André (1986) ressaltam que esse instrumento apresenta uma vantagem sobre as outras técnicas, pois permite a captação imediata e corrente das informações que se deseja obter.

As entrevistas realizadas durante a pesquisa seguiram alguns pressupostos destacados por Bogdan e Biklen (1994), pois foi preocupação da pesquisadora que os entrevistados estivessem à vontade para relatarem suas experiências e reflexões sobre o trabalho no CPV, assim como o estabelecimento de uma relação de confiança para eles poderem expor suas visões sobre o ser professor nesse contexto. Assim, foi imprescindível esclarecer os objetivos do estudo e reafirmar que a coleta de dados era necessária para recolher informações cujo propósito era responder a uma questão de pesquisa, e não para avaliá-los ou criticar suas ações pedagógicas. Não se pode esquecer que o papel do pesquisador é compreender as diferentes perspectivas dos entrevistados e as razões que os levam a assumi-las. Procurou-se, também, deixar claro que se trata de um trabalho confidencial, além de estimular os entrevistados ou encorajar os sujeitos a dizerem o que pensam e sentem; deixá-los à vontade para silenciarem e organizarem seu pensamento, sempre que considerarem conveniente.

Optou-se nesse estudo por realizar a análise temática dos dados, uma das modalidades de análise que compõe a técnica de análise do conteúdo descrita por Minayo (1993). Sobre a análise temática, Minayo (1993, p. 209) afirma que "fazer uma análise temática consiste em descobrir os núcleos de sentido que compõem uma comunicação cuja presença ou freqüência signifiquem alguma coisa para o objeto analítico visado”.

A análise das entrevistas permitiu a identificação de três elementos importantes 
na configuração da aprendizagem da docência: o início da docência, as mudanças ocorridas em suas práticas e a influência do contexto do CPV para a formação docente.

O processo de análise iniciou-se com a transcrição das fitas cassete que continham as respostas dadas por cada um dos participantes da pesquisa às questões da entrevista. A segunda etapa consistiu na leitura e releitura dos dados, com intuito de familiarização, sistematização e definição dos aspectos mais relevantes que comporiam a descrição dos dados. Ao longo da análise os professores serão identificados por meio de nomes fictícios.

O pesquisador qualitativo, segundo Bogdan e Biklen (1994), interessa-se pelo sentido que as pessoas atribuem às suas vidas e ações, preocupando-se fortemente com a perspectiva dos participantes. Sendo assim, o processo de análise dos dados é repleto de idas e vindas, na tentativa de compreender os significados atribuídos pelos participantes da pesquisa às experiências vividas.

Os dados apontaram as maiores dificuldades dos professores no início de sua experiência docente, as mudanças ocorridas em sua prática desde o início e a influência do curso de formação inicial para a sua formação docente. Indicaram, também, as aprendizagens e vivências docentes em instâncias do projeto consideradas formativas, como: elaboração de simulados para os alunos, participação em reuniões gerais e pedagógicas, e participação em processos seletivos para professores e para os alunos.

Procurou-se evidenciar os aspectos comuns e divergentes dos professores sobre o processo de aprendizagem da docência vivido por eles. A análise de conteúdo das respostas possibilitou encontrar concepções dos sujeitos sobre o conhecimento pedagógico e os conhecimentos específicos da área do curso de formação de cada um e da disciplina que ministram, e a mudança de suas concepções durante a experiência docente no projeto. Além disso, mostrou como são as relações de aprendizagem desses professores com os seus pares e com os alunos do CPV.

Os professores apresentam, em seus relatos, aspectos de suas trajetórias pessoais, elementos que contribuíram para a sua formação docente, seja por meio das experiências como alunos e/ou por meio das reflexões que fazem de sua própria prática ao longo dela. Apresentam também elementos de contexto, ou seja, experiências vividas no local de trabalho que foram essenciais para a construção de sua base de conhecimento para a docência.

\section{A formação docente no Curso Pré-Vestibular da UFSCar}

\section{O início da docência}

Ao fazerem referência ao início da docência, os professores evidenciam a influência de elementos da experiência adquirida como alunos em todos os níveis de ensino, não necessariamente a mais recente, mas as experiências mais significativas e que convergem, portanto, com as suas concepções sobre o ensino, aprendizagem, alunos e o ser professor efetivamente. Tal saber é definido por Imbernón (2000) como o conhecimento pedagógico comum e é adquirido ao longo da escolaridade, na qual se assumem muitas vezes estereótipos e esquemas que precisam ser superados. Com base nesse saber, os professores sentem-se mais ou menos autônomos, seguros e independentes para agirem como agem e tomarem as decisões que tomam no cotidiano da sala de aula, seja no planejamento ou na condução de suas aulas. 
[Na formação] aprendi aquilo que eu não gosto que os professores façam. Não em termos de conteúdo, mas em termos de posicionamento profissional mesmo. Muitos professores usam só data show e ficam lendo, alguns só lêem, não explicam, não dão tanta atenção para os alunos, para eles os alunos devem saber tudo, não fazem perguntas, alguns não são assim, mas alguns são. Para eles qualquer tipo de perguntas, mesmo as mais simples, talvez sejam perguntas idiotas, acham que o aluno deve saber. Eu não penso dessa forma. Penso que o aluno não tem a obrigação de saber, porque talvez tenha acontecido algum lapso na comunicação, (e não por falha dele) talvez por falha do professor, que ele não tenha conseguido aprender. (Daniel)

As dificuldades encontradas pelos professores no início da docência perpassam a preocupação com o conteúdo específico, o planejamento do curso, a seleção de conteúdo, a postura que devem assumir para controlar a disciplina das turmas, a heterogeneidade dessas turmas, a forma de ensinar, a organização da lousa, entre outros tópicos relacionados ao processo de ensino e aprendizagem.. É possível perceber que as preocupações dos participantes centram-se mais no como ensinar, que envolve atitudes diante da situação de ensino, do que no ser professor, que extrapola o âmbito da sala de aula, envolvendo regras, responsabilidades, formas de agir e pensar como profissionais emergentes, conforme Knowles (1994).

Quando eu entrei no projeto e comecei a dar aula eu não me preocupava muito com o aluno não, no sentido de quem é esse aluno, de onde veio esse aluno, eu sabia que vinha de escola pública e, geralmente ele tinha mais dificuldades. Mas o que eu queria era demonstrar domínio de conteúdo e não ter problema com a aula, não ter risco de falar besteira ou dar um fora muito grande. Eu achava que se eu falasse corria o risco de perder a sala, o aluno pensaria: "Pô, aquele cara falou asneira. $\mathrm{O}$ cara não sabe?” (Daniel)

Preparar aula, em termos de conteúdos mesmo, principalmente, a Citologia é um conteúdo muito vasto e alguns livros trazem algumas coisas erradas. Então, na hora de preparar as aulas eu não sabia como abordar, eu procurava vários livros e cada um falava uma coisa diferente, então, eu tinha que procurar em muitos. Estudar muito para conseguir preparar uma aula que eu achava que era ideal, que estava com os conceitos não tão errados como traziam os livros. (Eduardo)

Os professores compreendem que os conhecimentos específicos aprendidos durante a formação inicial proporcionam maior segurança no momento de ensinar e são mais facilmente reportados à sala de aula. Sobre os conteúdos pedagógicos aprendidos em curso de licenciatura, concordam que contribuem para compor o conhecimento pedagógico geral, no entanto não percebem a presença desse conhecimento na prática docente.

Pode-se afirmar que os participantes da pesquisa passam por um processo de compreensão sobre os conhecimentos adquiridos na Universidade, sobre os limites da utilização desses conhecimentos em suas práticas e como transformá-los em práticas pedagógicas. Esteve (1995), apoiando-se em Veenman (1984), afirma que, ao iniciarem suas carreiras, os professores sentem-se desamparados e inseguros frente à realidade escolar com a qual se deparam, pois frequentemente ela não corresponde aos esquemas ideais obtidos no curso de formação inicial para a docência.

Sobre isso, Eduardo afirma: “[...] na graduação, as disciplinas são fragmentadas. Em Citologia, você vê tecido apenas, não 
vê a conectividade daquilo com outras coisas. Eu tive uma grande dificuldade no começo [...] por não ter essa integração entre as áreas”. Dessa forma, é possível afirmar que o contexto é elemento determinante e gerador da configuração da prática docente, de suas mudanças e da construção de teorias pessoais.

Os professores entrevistados apontam, finalmente, as aprendizagens obtidas na prática docente no CPV, como: questionar de maneira adequada os alunos, elaborar questões para avaliação, selecionar conteúdos, desenvolver um método de estudo, lidar com a diversidade de pensamentos, valorizar os alunos e suas dificuldades e, ainda, ministrar aulas.

Como questionar os alunos, eu não aprendi nas aulas de graduação. Foi aqui. [...] como procurar fazer questões melhores para avaliação também não existiu na minha graduação [...] como estudar também, antes de entrar aqui estudava como louco várias coisas. Hoje, meu estudo é mais direcionado (Eduardo).

A seguir, serão apresentadas as mudanças que ocorreram na vivência docente dos participantes ao longo de sua prática e que contribuíram para a (re)significação do ensino e (re)construção do conhecimento pedagógico do conteúdo ou de aprender a ensinar e a ser professor.

\section{As mudanças ocorridas nas práticas dos professores do CPV}

Os participantes da pesquisa revelam mudanças na forma de ensinar desde o início da docência. Expressam que as mudanças mais significativas envolvem a organização e uso da lousa; hoje, tentam sintetizar os aspectos mais importantes do conteúdo de forma lógica e clara, tendo em vista a compreensão do aluno; passam a ter preocupação maior com a aprendizagem dos alunos; falam pausadamente, de maneira a serem compreendidos por eles; sentem-se mais seguros quanto ao domínio de conteúdo; adquirem capacidade de se expressar em público; passam a ser mais rígidos quanto à disciplina em sala de aula, quando observam essa necessidade; desenvolvem habilidade de selecionar conteúdos e administrar o tempo em aula. Enfim, revelam mudanças importantes nas estratégias de ensino. Nesse sentido, o conhecimento pedagógico geral, difundido por Shulman (1986), merece destaque. Os professores passam a pensar em formas de transformar o conhecimento específico da matéria que lecionam em conteúdos ensináveis - conhecimento pedagógico do conteúdo.

Ao deixarem a preocupação com a sua performance (que envolve o medo de errar, a demonstração de domínio de conteúdo, a tentativa de superar a insegurança de lidar com o público, entre outros), passam a compreender as dúvidas, os anseios, as aprendizagens adquiridas pelos alunos. Passam, portanto, a (re)construir suas práticas com base nesses elementos, que são fornecidos pelos alunos, no momento em que ensinam. Superando esses obstáculos, o professor é capaz de refletir sobre o ser aluno, o ser professor e sobre o processo de ensino-aprendizagem. Nessa direção, o professor Daniel comenta: “Quando eu entrei no projeto e comecei a dar aula, eu não me preocupava muito com o aluno não, [...] o que eu queria era demonstrar domínio de conteúdo".

Há elementos de sua prática que os professores consideram que precisam ser melhorados: 
Ainda tenho que melhorar um pouco em como formular as questões durante a aula (Eduardo).

Várias vezes eu continuo fazendo fórmulas sem colocar índice por causa de tempo (Márcio).

Eu sempre acho que eu não sei o suficiente para dar aula. Eu acho que eu precisava ter mais exemplos (Letícia).

Nunca vou estar num nível pedagógico perfeito; nunca meu domínio de conteúdo será perfeito. (Samuel)

Quando eu olho no conteúdo e vejo que é extenso, eu sei que preciso fazer uma seleção, eu ainda não consigo abrir mão de algumas coisas (Daniel).

É possível notar que as modificações apontadas pelos professores envolvem reflexões sobre o como ensinar, processo esse que envolve o desenvolvimento da compreensão de si mesmo, dos alunos e do conteúdo, visando à aprendizagem efetiva dos alunos.

\section{A influência do contexto do CPV para a formação docente}

Os professores explicitam como percebem e identificam as influências dos elementos de contexto para a prática docente. Os elementos de contexto, tratados aqui, fazem parte de um conjunto de atividades propostas pelo projeto, envolvendo o trabalho de todo o corpo docente ou pelo menos dos professores de uma área do conhecimento. São espaços que propiciam ao corpo docente maior compreensão e envolvimento sobre os cursos do projeto, e ainda proporcionam reflexões sobre o ensinar e o ser professor. Nesses espaços, os professores decidem sobre questões administrativas e questões pedagógicas constantemente, pois todos no projeto são responsáveis por exercerem algumas funções que demandam organização e também deliberam sobre a organização geral do projeto.

Os professores, portanto, manifestam suas opiniões sobre esses dois aspectos, sugerem melhores maneiras de conduzir os processos decisórios, que ocorrem essencialmente nas reuniões gerais e pedagógicas; expressam suas reflexões sobre aspectos pedagógicos discutidos nas reuniões pedagógicas; exprimem suas compreensões sobre avaliação; questionam a função dos exames simulados para os alunos e professores; repensam suas estratégias e propósitos para o ensino a partir destes; e evidenciam as aprendizagens obtidas nos espaços formativos do projeto. Apontam, ainda, suas compreensões, sugestões, análises e aprendizagens acerca dos processos seletivos para o corpo docente e discente do projeto.

Na parte pedagógica eu acho que fica um
pouco a desejar, eu acho que nas reuniões
a gente não discutia muito isso. Mas, um
exemplo que eu posso dar que contribui
para a sala de aula mesmo, foi a parte de
formular questões para simulados e para
avaliação da aprendizagem deles, porque
eu acho que, vendo como o coordenador
administrativo selecionava as questões e
as críticas que ele fazia das questões, eu
comecei a perceber o que era importante
ressaltar numa questão e o que não era,
como formular uma pergunta bem clara.
(Letícia)

Sobre as reuniões gerais, os participantes de maneira geral concordam que são pouco objetivas e com longa duração, tornam-se maçantes devido às repetições de opiniões dos integrantes do grupo, as pautas nem sempre são discutidas e/ou concluídas e ainda repetem-se as discussões da reunião anterior a cada início de uma nova. 
Eu acho que tem níveis de decisões administrativas que é importante os professores falarem. Por exemplo, se muda ou não de prédio vai influenciar diretamente no trabalho deles, se põe 80 ou 20 pessoas nas salas de aula vai influenciar. Mas, [...] a questão de pagamento dos alunos eu acho, que é uma coisa totalmente da administração ver como vai organizar (Daniel).

Os participantes consideram que os assuntos administrativos devem ser tratados pela comissão coordenadora, que existe para isso. Preferem que se discutam nesse espaço apenas as questões pedagógicas e os aspectos administrativos que influenciarão diretamente no trabalho do corpo docente.

O processo seletivo de professores é o momento em que os docentes examinadores selecionam o candidato que consideram ser adequado para ocupar a vaga de professor e/ ou monitor. Esse processo é composto por uma avaliação de conhecimentos específicos - prova escrita sobre conteúdos da área de interesse -, uma avaliação didática sobre um tema previamente definido e divulgado para os candidatos, e entrevista.

A prova escrita é elaborada por professores e monitores da área para a qual se está realizando o processo de seleção; cabe também a eles definir o tema da avaliação didática, bem como participar da banca examinadora juntamente com um ou mais membros da comissão coordenadora do projeto, a qual, eventualmente, conta com a presença de professores da própria universidade e de fora dela (professores de uma escola de ensino médio da rede privada da cidade de São Carlos, que têm colaborado com o projeto desde o seu início).

Para os professores, esse processo avalia os conhecimentos específicos e pedagógicos dos candidatos por meio da avaliação escrita e didática. Acreditam que a prova escrita é um bom instrumento para avaliação dos conhecimentos específicos que os candidatos possuem sobre a matéria a ser ensinada e que, na avaliação didática, o destaque está no conhecimento pedagógico, essencialmente no como ensinar. Na avaliação didática, costumam observar a postura do candidato frente à situação de ensino; a reação dos candidatos diante dos questionamentos da banca examinadora; se os candidatos olham para todos ou se falam de costas para a banca, como explicam o conteúdo, como organizam a lousa. Observam, também, o raciocínio escolhido pelos candidatos para expor o conteúdo, o repertório representacional usado por eles para facilitar a compreensão do conteúdo.

$\mathrm{Na}$ prova escrita elaborada por algumas áreas, por exemplo, há questões que exigem que o candidato explique determinado conteúdo como se estivesse ensinando um aluno do ensino médio, atrelando os conhecimentos específicos e pedagógicos. Nessas questões, é possível notar algumas estratégias que o candidato utilizaria, a forma como compreende o conteúdo e o torna ensinável aos seus alunos. Assim, Eduardo relata: “[...] teve uma prova que nós fizemos uma vez que eu considero a melhor, tinha umas questões relacionadas ao ensino. O candidato iria elaborar uma questão para seus futuros alunos em relação aos dados que nós demos”.

Os participantes expressam-se também sobre o processo seletivo de alunos, suas participações, percepções e aprendizagens a partir do contato com os candidatos - futuros alunos do CPV. É pertinente ressaltar que esse processo de seleção é composto por: (1) avaliação socioeconômica, que é feita a partir de informações dos candidatos, fornecidas em entrevista estruturada orientada por um 
questionário ${ }^{2}$ e comprovadas por documentos exigidos aos mesmos; e (2) avaliação de habilidades básicas de leitura, escrita e cálculo matemático elementar, realizada por meio de uma prova com questões de múltipla escolha. O processo seletivo é organizado pela comissão coordenadora do projeto e realizado por ela e pelo corpo docente do cursinho.

As características da prova de seleção dos alunos para ingresso no curso foram definidas a partir do pressuposto de que os alunos, em sua ampla maioria, provavelmente não teriam tido contato com a maior parte dos conteúdos previstos na programação dos vestibulares. Diante disso, a orientação pedagógica de um projeto que tem como perspectiva a formação do aluno considera que o processo de aprendizagem dos conteúdos da programação dos vestibulares deve ocorrer no ‘cursinho'. Assim, as aulas desse 'cursinho' não se caracterizariam como aulas de revisão de conteúdos, mas como aulas em que houvesse ensino efetivo de tais conteúdos. Para tanto, os candidatos deveriam ser avaliados em relação a algumas de suas potencialidades para aprender, tais como a capacidade de compreensão de textos de diferentes linguagens, a capacidade de utilizar informações disponíveis para resolver problemas e o conhecimento de operações matemáticas elementares. Essas habilidades dariam condições básicas para os alunos assistirem às aulas, participarem delas, estudarem e, de fato, aprenderem. Por isso,

\footnotetext{
${ }^{2}$ Nos três primeiros anos do projeto, os candidatos preenchiam um questionário. Em 1999, esse preenchimento foi feito individualmente pelo candidato. Nos anos de 2000 e 2001, foi feita uma aplicação coletiva, na UFSCar, em dia previamente definido no calendário do processo de seleção. Problemas relacionados, por exemplo, à falta de preenchimento de dados no questionário levaram à decisão de realizar uma entrevista estruturada para essa coleta de dados sobre os candidatos.
}

a avaliação a que são submetidos os candidatos ao ‘cursinho' objetiva diagnosticar algumas condições mínimas para aprender, e não verificar seu domínio de conhecimentos específicos. A avaliação socioeconômica tem caráter eliminatório e a prova, caráter classificatório. Assim, todos os que são aprovados na avaliação socioeconômica são considerados público potencial do projeto e são classificados pela nota da prova para o preenchimento das vagas. Aqueles alunos que não obtêm classificação suficiente para obtenção de vaga na primeira chamada para matrícula compõem uma lista de espera, podendo ser chamados posteriormente.

Os professores entrevistados consideram o processo seletivo bastante sério e bem organizado, destacando as aprendizagens pessoais oriundas das vivências nesse processo.

No começo eu achava que eu estava fazendo um favor para eles, principalmente quando eu comecei a trabalhar como voluntário. Eu estava tentando pagar alguma coisa que a sociedade tinha me dado. Hoje eu penso diferente, eu penso que eles estão me fazendo um favor muito grande por estar dando espaço para eu conseguir lecionar, me desenvolver, não só como professor, mas como ser humano também [...]. Você começa a dar valor para as coisas que antes não dava. (Eduardo)

Acreditam esses professores que o conhecimento sobre os alunos influencia nas estratégias de ensino que pretendem utilizar, na dosagem do conteúdo, na inferência de ritmo às aulas, auxilia na decisão sobre os materiais a serem utilizados e na definição dos objetivos do ensino. $\mathrm{O}$ conhecimento sobre o público atendido os faz refletir sobre o que é mais importante: ensinar conceitos básicos, ou ensinar para prepará-los para o vestibular; cumprir ou não o cronograma de conteúdos 
proposto pelo currículo, ou preocupar-se em ensiná-los de fato. Tais questionamentos permanecem, ao longo da prática desses professores, mesmo que escolham uma das opções, ou resolvam mesclá-las. Esses questionamentos são desencadeadores de muitas reuniões pedagógicas no projeto e, também, muitas vezes, são esses questionamentos que definem novos rumos ao projeto, como, por exemplo, a criação da modalidade de dois anos, oferecendo mais tempo aos alunos que necessitam adquirir os conhecimentos básicos que compõem as disciplinas do currículo e que são exigidos pelos exames vestibulares. Essas discussões em grupo promovem o desenvolvimento profissional dos professores e, ao mesmo tempo, o aperfeiçoamento do projeto ao longo do tempo, acompanhando as mudanças do público atendido e dos professores e equipe gestora.

\section{Considerações finais}

Devido à complexidade de conhecimentos e ações educativas que envolvem o ser professor e o ensinar, retratar a formação de professores é uma difícil tarefa. É uma questão que não se esgota e os trabalhos desenvolvidos sobre essa temática não são conclusivos, não encerram as discussões sobre o início da carreira, suas dificuldades e o rol de aprendizagens que constituem o desenvolvimento profissional docente.

A despeito da existência de muitas pesquisas na área educacional sobre a formação de professores, aprendizagem da docência e início da atividade profissional docente, não é possível definir um pacote único de conhecimentos que o professor deve possuir para ensinar, ou de informações sobre todas as aprendizagens necessárias à sua atuação. Muitos estudos contribuíram para que alguns desses conhecimentos e aprendizagens fossem desvelados, no entanto os cursos de formação inicial não conseguem proporcionar aos seus alunos conhecimentos suficientes para o enfrentamento da realidade escolar. Há conhecimentos, ainda, que apenas a prática docente é capaz de proporcionar, como aqueles que envolvem o contexto escolar, o manejo da sala de aula, as regras que regem as instituições de ensino, entre outros.

A pesquisa aqui apresentada dedicouse à compreensão da aprendizagem da docência sob a perspectiva dos professores do Curso Pré-Vestibular das UFSCar, tendo como eixos principais de análise o início da carreira e suas dificuldades, e as contribuições da formação inicial para o exercício da docência, da prática no CPV e dos elementos de contexto para a formação docente.

No início da docência, os professores do CPV vivenciaram um intenso processo de estabilização e desestabilizações de suas compreensões sobre os conteúdos que lecionam e sobre o ensino efetivamente. Eles apontaram preocupação com o domínio do conteúdo específico, ao mesmo tempo em que lidaram com as consequências de uma formação fragmentada.

Os professores que atuavam na área de conhecimento correspondente à área do curso de formação inicial perceberam a necessidade de alinhavar, fazer as amarrações dos conteúdos aprendidos a fim de se sentirem seguros para ensinar. Aqueles que não atuavam na mesma área de conhecimento do curso de formação inicial empenhavam-se mais fortemente para dominar o conteúdo a ser ensinado, construindo suas compreensões sobre a matéria.

Os professores compreenderam que os conhecimentos específicos aprendidos durante a formação inicial proporcionam 
maior segurança no momento de ensinar, e são conhecimentos que são mais facilmente reportados à sala de aula. Sobre os conteúdos pedagógicos aprendidos em curso de licenciatura, concordaram que contribuem para compor o conhecimento pedagógico geral, porém não percebiam a presença desse conhecimento na prática docente.

Sobre isso, sugeriram que os cursos de formação docente trabalhem mais fortemente com estudos de caso voltados às principais demandas do início da docência, como a disciplina, a avaliação, entre outros. Outra sugestão é proporcionar espaço para que os alunos das licenciaturas possam ministrar aulas simuladas, não em caráter de seminário, mas em caráter de avaliação didática. Nessas aulas o professor formador deveria apontar as falhas e os aspectos positivos sobre o conteúdo abordado e também sobre a performance. Essas são questões consideradas carentes nos cursos de formação inicial para a docência.

Os professores deste estudo apresentaram algumas dificuldades no início da docência, as quais abrangiam características pessoais (serem mais ou menos sérios, fazerem brincadeiras ou não) e o como ensinar: a dificuldade de conciliar o curso de formação inicial com a atividade docente, de lidar com o público com o receio de errar, ou de não conseguir responder aos anseios dos alunos. Mostraram preocupação com o domínio do conteúdo, a seleção dos conteúdos a serem ensinados, a maneira de torná-los compreensíveis e o como avaliar o desempenho de seus alunos.

É possível notar que quando os professores passam por um processo de estabilização representado pela superação de algumas dessas dificuldades, eles aperfeiçoam e/ ou modificam suas estratégias de ensino. Ao sentirem-se mais seguros quanto a alguns elementos que compõem o como ensinar, os professores passam por um processo de descentralização de suas preocupações sobre suas próprias performances e ações para focalizarem seus alunos quanto às suas dificuldades, anseios e compreensões sobre os conteúdos. (Re)conceituam o ensino de acordo com as demandas do contexto escolar.

Além de lidarem com os meandros que envolvem o início da experiência docente e o como ensinar, os professores do Curso Pré-Vestibular da UFSCar envolvem-se em espaços que extrapolam o âmbito da sala de aula, tendo em vista a forma de gestão e organização que caracteriza o projeto.

O CPV é um projeto que permite aos professores a exploração em espaços, funções e responsabilidades que as instituições regulares de ensino, geralmente, não permitem. Os professores deliberam sobre os rumos pedagógicos e organizacionais, assumem responsabilidades no âmbito de coordenação - fazendo parte do grupo coordenador, ou agindo como coordenadores de suas áreas de atuação - compartilham com seus pares seus anseios e propõem soluções, havendo negociações de processos, conteúdos e dinâmicas.

Em síntese, foi possível constatar que há conhecimentos - como a segurança e a descentralização de si mesmos, o aperfeiçoamento de práticas de ensino, a explanação do conteúdo na lousa e a elaboração de questões, entre outros - que os professores adquirem apenas no decorrer da prática docente.

Alguns elementos de contexto contribuem para repensar a prática docente e sua consequente (re)significação por meio da aprendizagem em várias instâncias. Neste estudo, esses elementos são: elaboração dos simulados; experiência anterior como monitor; participação nas reuniões pedagógicas; planejamento em grupo de 
avaliações (simulados e processo seletivo de professores e alunos) e atividades de ensino; participação da gestão de forma comprometida, a fim de definir os rumos da organização escolar. Houve também uma revisão de questões próprias da docência - elaboração e aplicação do planejamento, ação pedagógica referente aos conteúdos, desenvolvimento das aulas e aprendizagem dos alunos, trato com os alunos e sua avaliação - bem como a necessária reflexão sobre todo esse processo. Para os professores as aprendizagens advindas das reuniões pedagógicas e da experiência foram destacadas como as mais relevantes.

Os professores indicaram suas teorias pessoais ao evidenciarem as mudanças ocorridas em suas práticas, os motivos que atribuem a elas e a importância das mesmas. Destacaram que essas mudanças têm origem na preocupação com a aprendizagem efetiva dos alunos, nas próprias reflexões sobre a prática, nas indicações dos alunos e nas aprendizagens docentes relacionadas à gestão escolar.

É possível perceber que os professores constantemente alteraram seus quadros referenciais para o ensino, ao (re)significarem as dificuldades do início da docência sobre os conteúdos a serem ensinados, de que forma e como ensiná-los, tendo em vista a complexidade, a função social e a acessibilidade da prática docente destacadas por Imbernón (2000).

\section{Referências}

BOGDAN, C. R.; BIKLEN, S. Investigação qualitativa em educação. Porto: Porto Editora, 1994.

ESTEVE, J. M. Mudanças sociais e função docente. In: NÓVOA, António (Org.). Profissão professor. Porto: Porto Editora, 1995.
IMBERNÓN, F. Formação docente e profissional: formar-se para a mudança e a incerteza. São Paulo: Cortez, 2000.

KNOWLES J. G.; COLE, A. L.; PRESSWOOD, C. Through preservice teachers' eyes: exploring field experiences through narrative and inquiry. N.Y.: Macmillan College Publishing Company, 1994.

LUKDE, M.; ANDRÉ, M. E. D. Pesquisa em educação: abordagens qualitativas. São Paulo: EPU, 1986.

MINAYO, M. C. S. O desafio do conhecimento: pesquisa qualitativa em saúde. São Paulo: Hucitec-Abrasco, 1993.

MIZUKAMI, M. G. N. Formadores de professores, conhecimentos da docência e casos de ensino. In: REALI, A M. M. R.; MIZUKAMI, M. G. N. Formação de professores, práticas pedagógicas e escola. São Carlos: EdUFSCar, INEP,COMPED, 2000.

et al. Escola e aprendizagem da docência: processos de investigação e formação. São Carlos: EdUFSCar, 2002.

. et al. A reflexão sobre a ação pedagógica como estratégia de modificação da escola pública elementar numa perspectiva de formação continuada no local de trabalho. In: ENDIPE, 9, 1998. Anais... Águas de Lindóia, 1998.

Aprendizagem da docência: algumas contribuições de L. S. Shulman. Revista Educação, Santa Maria, v. 29, n.2, p. 33-49, 2004.

NÓVOA, A. Para o estudo sócio-histórico da gênese e desenvolvimento da profissão docente. Teoria e Educação, n.4, p.109-139, 1991. 
PERDIGÃO, A. L. Projeto curso prévestibular da UFSCar. São Carlos, 2005. (Texto de circulação interna).

RICHERT, A. E; SHULMAN, L. S.; WILSON, S. M. “150 different ways” of knowledge in teaching. In: CALDERHEAD, James. Exploring teachers' thinking. London, Cassel Educational Limited, 1987.

TANCREDI, R. M. S. P. O exercício da profissão de professor: questões da cultura profissional e sua profissionalização. São Carlos: EdUFSCar, 2008.

Enviado em: 07/12/2009

Aceito em: 25/02/2011 